\title{
UPAYA MENINGKATKAN KETERAMPILAN BERMAIN SEPAKBOLA MELALUI PENDEKATAN TAKTIS
}

\author{
Suhari \\ SMP Negeri 2 Garawangi \\ email: suharigodong@gmail.com
}

\begin{abstract}
Abstrak
Penelitian ini dilatarbelakangi oleh keterampilan bermain sepakbola siswa kelas VIII F SMP Negeri 2 Garawangi yang masih rendah sehingga mempengaruhi terhadap capaian nilai sebagian besar siswa dibawah KKM dengan nilai 73. Tujuan dari Penelitian Tindakan kelas ini untuk memperbaiki untuk memperbaiki proses dan hasil belajar keterampilan bermain sepakbola melalui suatu pendekatan pembelajaran taktis guna mencapai keberhasilan pengajaran Pendidikan Jasmani. Metode yang digunakan yaitu Penelitian Tindakan Kelas (PTK) dengan dua siklus yaitu siklus I pertemuan 1-2 dan siklus II pertemuan 3-4. Populasi penelitian siswa kelas VIII berjumlah 245, sedangkan sampel penelitian kelas VIII F berjumlah 33 siswa. Instrument penelitian yang digunakan untuk mengukur keterampilan bermain sepakbola adalah Game Performance Assessment Instrument (GPAI). Teknik analisis data yang digunakan yaitu; 1) data kuantitatif berupa penilaian ketuntasan belajar, dan 2) data kualitatif dipaparkan dalam kalimat yang dipisahkan menurut kategori untuk memperoleh kesimpulan. Hasil penelitian menunjukkan bahwa pendekatan taktis sangat tepat untuk meningkatkan keterampilan bermain sepakbola siswa kelas VIII F SMP Negeri 2 Garawangi. Hal tersebut di tunjukan dari hasil analisis yang didapatkan bahwa nilai rata-rata pada setiap siklus yang meningkat. Pada siklus I nilai rata-rata nilai siswa sebesar 62,27 sedangkan pada siklus II nilai hasil belajar siswa rata-ratanya sebesar 76,76 ini menandakan siswa sudah mencapai KKM sehingga dengan diterapkannya pendekatan taktis dapat meningkatkan keterampilan bermain sepakbola, hal ini di tunjukan bahwa prosentase ketuntasan belajar pada siklus I ke siklus II mengalami peningkatan yang tinggi yaitu dari $20 \%$ menjadi $73 \%$.
\end{abstract}

Kata Kunci: Pendekatan, taktis, Keterampilan, Sepakbola

\begin{abstract}
This research is motivated by the skill of playing football of students of class VIII F junior school 2 Garawangi which still low so that influence to achievement value of majority of student under KKM with value 73. Purpose of Research This action class to improve to improve process and result learn skill of playing football through A tactical learning approach to achieve the successful teaching of Physical Education. The method used is Classroom Action Research (PTK) with two cycles ie cycle I meeting 1-2 and cycle II meeting 3-4. The research population of Grade VIII students is 245, while the research sample of class VIII F is 33 students. The research instrument used to measure the skills of playing football is the Game Performance Assessment Instrument (GPAI). Data analysis techniques used are; 1) quantitative data in the form of a thorough assessment of learning, and 2) qualitative data presented in sentences separated by category to obtain conclusions. The results showed that the tactical approach is very appropriate to improve the skills of playing football students of class VIII $F$
\end{abstract}


junioe school 2 Garawangi. It is shown from the analysis results obtained that the average value of each cycle increases. In the first cycle the average score of students score of 62.27 whereas in the second cycle of student learning outcomes average of 76.76 indicates that students have reached the KKM so that with the application of tactical approach can improve the skills of playing football, it is in show that The percentage of learning mastery in cycle I to cycle II has increased from $20 \%$ to $73 \%$.

Keywords: Tactical, Approach, Skill, Football

(c) 2017 STKIP Muhammadiyah Kuningan 
PENDAHULUAN

Pendidikan jasmani (penjas) merupakan bagian penting dari proses pendidikan. Melalui penjas yang diarahkan dengan baik, anak-anak akan mengembangkan keterampilan yang berguna bagi pengisian waktu senggang, terlibat dalam aktivitas yang kondusif untuk mengembangkan hidup sehat, berkembang secara sosial, dan menyumbang pada kesehatan fisik dan mentalnya. Meskipun penjas menawarkan kepada anak untuk bergembira, tidaklah tepat untuk penjas diselenggarakan sematamata agar anak bergembira dan bersenang-senang. Seperti yang dikemukakan oleh Husdarta (2011:18) yaitu "Pendidikan jasmani adalah proses pendidikan melalui aktivitas jasmani, permainan atau olahraga yang terpilih untuk mencapai tujuan pendidikan. Definisi tersebut mengukuhkan bahwa penjas merupakan bagian yang tak terpisahkan dari pendidikan umum. Tujuannya adalah untuk membantu anak agar tumbuh dan berkembang secara wajar sesuai dengan tujuan pendidikan nasional, yaitu menjadi manusia Indonesia seutuhnya. Pencapaian tujuan tersebut berpangkal pada perencanaan pengalaman gerak yang sesuai dengan karakteristik anak.

Sekolah Menengah Pertama (SMP) merupakan lembaga pendidikan yang berorientasi pada pengembangan siswa usia antara 12 - 15 tahun. Dalam tahap perkembangannya, siswa SMP berada pada tahap periode perkembangan yang sangat pesat dari segala aspek, yaitu perkembangan aspek kognitif, psikomotor, dan afektif. Materi yang di ajarkan pada mata pelajaran penjas terdiri dari beberapa pendekatan cabang olahraga. Jenis kegiatan yang diajarkan dilkasifikasikan ke dalam enam kategori diantaranya aktivitas permainan dan olahraga, aktivitas pengembangan, aktivitas uji diri, aktivitas ritmik, aktivitas air, dan aktivitas luar sekolah/alam bebas. Achmad dkk (2004: 16). Berdasarkan standar kompetensi dan kompetensi dasar kelas VIII SMP olahraga permainan bola besar merupakan materi yang wajib diberikan. Salah satu olahraga permainan bola besar yang sangat digemari oleh siswa yaitu sepakbola.. Permainan sepak bola merupakan olahraga permainan yang dimainkan dua tim, dimana masingmasing tim beranggotakan sebelas orang termasuk di antaranya penjaga gawang. Sucipto (2000: 7).

Untuk bermain sepakbbola dengan baik pemain dibekali dengan teknik dasar yang baik. Pemain yang memiliki teknik dasar yang baik pemain tersebut cenderung dapat bermain sepakbbola dengan baik pula. Ada beberapa teknik dasar yang perlu dimiliki pemain sepak bola adalah menendang (kicking), menyundul (heading), merampas (tackling), menggiring (dribbling), menghentikan (stoping), lemparan ke dalam (throw-in), dan menjaga gawang (goal keeping). 
Penguasaan teknik dasar bagi seorang pemain sepak bola adalah penting, karena sangat berkaitan dengan inti dari permainan sepak bola yaitu bertujuan untuk memasukan bola sebanyak-banyaknya ke dalam gawang lawan serta mempertahankan gawang sendiri dari serangan lawan agar tidak kemasukan bola oleh pihak lawan.

Dalam kaitannya dengan pelaksanaan pembelajaran pendidikan jasmani di sekolah perlu diterapkan sebuah model pembelajaran tertentu agar dapat mempermudah peserta didik dalam menyerap semua informasi yang disajikan oleh guru dan mampu membantu peserta didik memahami seluruh instruksi yang diberikan. Dalam kaitan permainan sepakbola dengan dunia pendidikan hendaknya permainan ini terus dikembangkan melalui pembelajaran yang terarah dan terencana melalui beberapa model pembelajaran yang sesuai dan alat yang tepat dengan karakteristik bahan pelajaran serta kondisi peserta didik. Beberapa cara mengajar tentang kemampuan keterampilan bermain sepakbola tersebut di antaranya dengan menggunakan penerapan pendekatan taktis. Mengenai hal ini, Subroto (2001:4) menjelaskan bahwa: "Tujuan pendekatan taktis dalam pembelajaran permainan adalah untuk meningkatan kesadaran siswa tentang konsep bermain melalui penerapan teknik yang tepat sesuai dengan masalah atau situasi dalam permainan."
Berkaitan dengan hal tersebut, pendekatan taktis dapat mendukung siswa kepada keinginan atau minat yang lebih besar dalam mempelajari dan bepartisipasi aktif dalam permainan sepak bola, sehingga dapat menumbuhkan dan meningkatkan kemampuan dalam bermainnya. Selain itu juga melalui pendekatan taktis pada permainan sepak bola bentuk pembelajarannya disiasati melalui kegiatan bermain sepak bola secara langsung dan menyeluruh. Artinya siswa belajar teknik dasar permainan sepak bola dilaksanakan melalui bentuk bermain sepak bola secara langsung, melalui pola-pola permainan yang akhirnya bertumpu kepada situasi yang sebenarnya.

Berdasarkan hasil observasi dan pengamatan di lapangan sebagian besar siswa kelas VIII F SMP Negeri 2 Garawangi masih kesulitan untuk melakukan suatu teknik yang tepat dalam situasi permainan sepakbola, kesulitan untuk membongkar pertahanan lawan, penempatan posisi yang kurang strategis ketika rekan sedang menguasai bola. Dengan kondisi demikian pemahaman dalam suatu permainan tidak maksimal sehingga berpengaruh terhadap hasil keterampilan bermain sepakbola. Hasil evaluasi menyatakan bahwa tingkat keberhasilan siswa dalam keterampilan bermain sepakbola masih dibawah nilai KKM 73 yang ditetapkan oleh guru penjas. Ditinjau dari permasalahan tersebut 
tentunya harus ada solusi yang tepat dan dapat meningkatkan keberhasilan siswa dalam keterampilan bermain sepakbola sesuai dengan KKM tersebut.

Dari pemaparan tersebut, penulis tertarik untuk memperbaiki proses dan hasil pembelajaran keterampilan bermain sepakbola melalui pendekatan taktis dengan Penelitian Tindakan Kelas (PTK). Penelitian tindakan ini bertujuan untuk menanggulangi masalah atau kesulitan dalam pendidikan dan pengajaran, melaksanakan program penelitian, memberikan pedoman bagi guru, untuk perbaikan proses dan hasil belajar siswa, dan juga juga memasukan unsur-unsur pembaharuan dalam sistem pendidikan dan pengajaran, Sanjaya (2013: 16).

\section{METODE}

Penelitian ini termasuk Penelitian Tindakan Kelas (PTK), karena dalam penelitian ini dilakukan untuk memecahkan permasalahan yang terjadi di kelas. PTK bertujuan memberikan sumbangan nyata peningkatan profesionalisme guru, menyiapkan pengetahuan, pemahaman dan wawasan tentang prilaku guru pengajar dan murid belajar. Pendekatan yang dilakukan adalah pendekatan kualitatif, sebab dalam melakukan tindakan kepada subyek penelitian sangat diutamakan adalah mengungkap makna tentang proses pembelajaran sebagai upaya meningkatkan motivasi, kegairahan dan hasil belajar melalui tindakan yang dilakukan. Penelitian tindakan kelas (PTK) adalah penelitian yang dilakukan oleh guru di kelasnya sendiri dengan cara (1) merencanakan, (2) melaksanakan, (3) mengamati, dan (4) merefleksikan tindakan secara kolaboratif dan partisipatif dengan tujuan memperbaiki kinerjanya sebagai guru, sehingga hasil belajar siswa dapat meningkat. Kusumah (2011: 9). Desain penelitian menggunakan empat tahapan seperti yang sudah dijelaskan di atas yaitu planning, acting, observing, dan reflecting yang terdiri dari dua siklus. Desain penelitian ini dapat dilihat pada gambar di bawah ini:

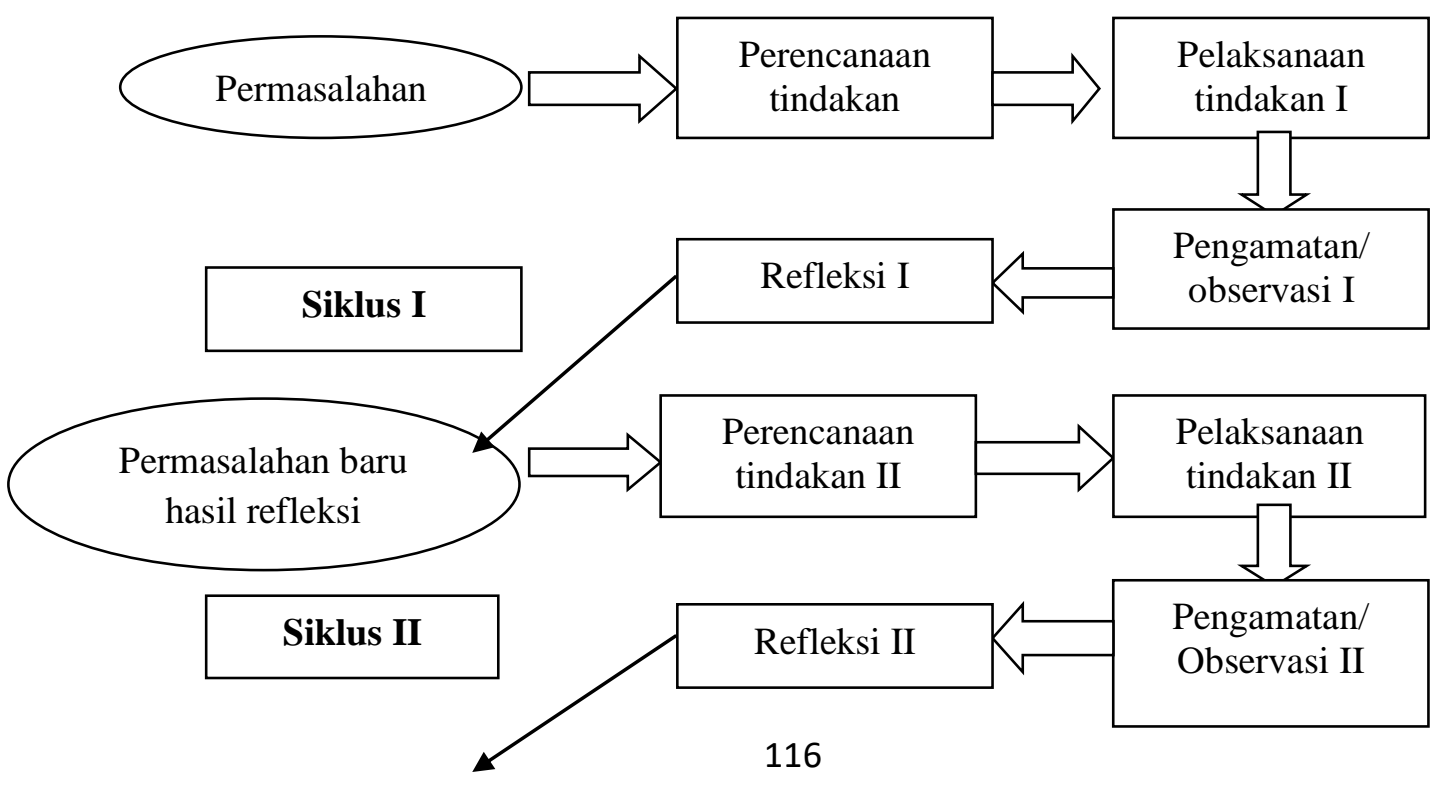




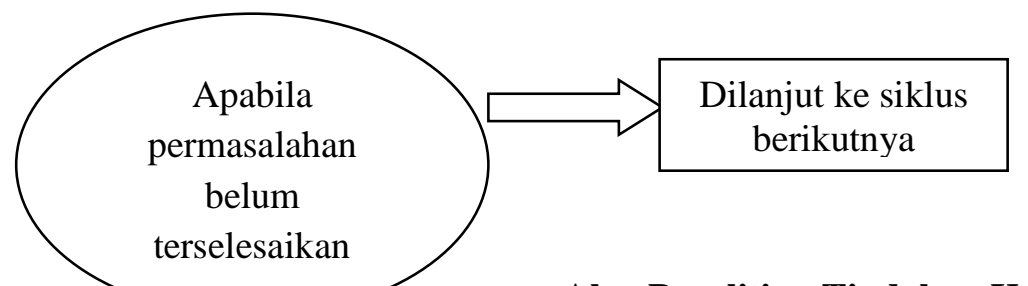

\section{Alur Penelitian Tindakan Kelas}

Sumber: Kemmis dan Taggart dalam Suharsimi (2010)

Populasi penelitian siswa kelas VIII

SMP Negeri 2 Garawangi berjumlah 245, sedangkan sampel penelitian kelas VIII F berjumlah 33 siswa, dikarenakan siswa kelas tersebut hasil belajar keterampilan sepakbolanya sebagian besar dibawah KKM. Instrumen penelitian untuk mengukur keterampilan bermain siswa dalam permainan sepak bola digunakan tes Game Performance Assessment Instrument (GPAI). Griffin, Mitchell dan Oslin (1997, hlm 219). Komponen yang digunakan dalam mengukur keterampilan bermain siswa (game performancel GP) dalam permainan sepak bola pada penelitian ini adalah:

1. Decision Making (DM) dengan kriteria: a. Pemain mampu untuk mengumpan kepada teman yang berada dalam posisi bebas tanpa kawalan, b. Pemain mampu menembak ketika berada dalam situasi yang tepat.

2. Skill Execution (SE): a. Menerima: mengontrol gerakan saat menerima umpan dan memposisikan bola, b. Mengumpan: bola dapat menjangkau target, c. Menembak: saat menembak bola menjangkau target.
3. Support Index (SI): pemain tampil untuk mendukung pergerakan pemain lain yang membawa bola dengan menghalangi pemain lawan atau bergerak ke posisi yang tepat untuk menerima umpan.

\section{HASIL PENELITIAN}

Data penelitian yang diperoleh berupa data hasil pengamatan dalam proses pembelajaran untuk masing-masing siklus. Data lembar observasi diambil dari observasi terhadap tindakan siswa dalam proses pembelajaran yang digunakan untuk mengetahui proses penerapan pendekatan taktis terhadap keterampilan bermain sepakbola siswa kelas VIII F SMP Negeri 2 Garawangi Kabupaten Kuningan.

Dengan menggunakan instrument Game Performance Assessment Instrument (GPAI), peneliti menilai pelaksanaan tindakan dalam rangka peningkatan keterampilan bermain sepakbola siswa selama 4 kali pertemuan yang terbagi dalam 2 siklus. Untuk selanjutnya, data hasil tes ini di bagi persiklus. Analisis dan refleksi untuk menentukan tindakan perbaikan. Sebaiknya untuk mengetahui peningkatan keterampilan bermain sepakbola, berikut ini di tampilkan data hasil tes di lapangan. 
Untuk menentukan kriteria keberhasilan tindakan dalam rangka peningkatan keterampilan bermain sepakbola, data hasil tes setiap siklus kita tabulasikan kemudian dianalisis dengan mean. Hasil rata-rata kedua siklus lalu kita bandingkan untuk mengetahui perkembangan mutu tindakan. Guna memperjelas hasil analisis dan memudahkan interpretasi, data peningkatan mutu tindakan akan ditampilkan dalam bentuk diagram batang. Analisis data berdasarkan pengukuran tes Game Performance Assessment Instrument (GPAI). Griffin, Mitchell dan Oslin (1997:219) selengkapnya sebagai berikut:

Tabel 1 Analisis Perbandingan Hasil Rerata Nilai Tindakan Siklus I dan siklus II

\begin{tabular}{|c|c|c|c|c|}
\hline No & Nama Siswa & Rerata Siklus I & $\begin{array}{c}\text { Rerata Siklus } \\
\text { II }\end{array}$ & Keterangan \\
\hline 1 & AGUS SETIAWAN & 76 & 82 & Meningkat \\
\hline 2 & AHMAT AGUNG MULYA & 57 & 75 & Meningkat \\
\hline 3 & ALFIN ADELIA & 69 & 81 & Meningkat \\
\hline 4 & ALIF FIRYALFADILAH & 54 & 73 & Meningkat \\
\hline 5 & ANA RAIS & 56 & 73 & Meningkat \\
\hline 6 & ANIS MARSELA & 56 & 73 & Meningkat \\
\hline 7 & DAVID RAMADHAN & 58 & 74 & Meningkat \\
\hline 8 & DEDE FAJAR & 72 & 86 & Meningkat \\
\hline 9 & GITA OKTAVIANI & 68 & 78 & Meningkat \\
\hline 10 & HERI IRWANTO & 76 & 82 & Meningkat \\
\hline 11 & IDA ROSIDA & 53 & 73 & Meningkat \\
\hline 12 & IRA & 54 & 75 & Meningkat \\
\hline 13 & $\begin{array}{l}\text { IRUL SYAHRUL } \\
\text { RAHMAN }\end{array}$ & 60 & 74 & Meningkat \\
\hline 14 & ISEU ISNAWATI & 65 & 78 & Meningkat \\
\hline 15 & LILI & 60 & 74 & Meningkat \\
\hline 16 & LUKMAN NULHAKIM & 58 & 73 & Meningkat \\
\hline 17 & MARDINI & 51 & 73 & Meningkat \\
\hline 18 & $\begin{array}{l}\text { MUHAMAD RIFKY } \\
\text { YANUAR }\end{array}$ & 75 & 81 & Meningkat \\
\hline 19 & NAUFALAR AR RAHMAN & 65 & 81 & Meningkat \\
\hline 20 & NAZAR GEBITEL & 56 & 73 & Meningkat \\
\hline 21 & NETI JUNETI & 60 & 75 & Meningkat \\
\hline 22 & NIDA NUR RISTIANI & 56 & 73 & Meningkat \\
\hline 23 & OMAH RAHMAH & 57 & 74 & Meningkat \\
\hline 24 & PINA NURHASANAH & 60 & 74 & Meningkat \\
\hline 25 & RAIHANSYAH & 62 & 77 & Meningkat \\
\hline 26 & RISKA & 58 & 74 & Meningkat \\
\hline 27 & SAHIRIN & 76 & 82 & Meningkat \\
\hline 28 & SELVY HANDAYANI & 72 & 86 & Meningkat \\
\hline 29 & SITI MUBAROKAH & 68 & 78 & Meningkat \\
\hline 30 & TIARA LISTIANI & 61 & 79 & Meningkat \\
\hline 31 & UDIN MAULANA & 69 & 81 & Meningkat \\
\hline 32 & YANTI SUGIHARTI & 60 & 74 & Meningkat \\
\hline 33 & AKBAR M & 57 & 74 & Meningkat \\
\hline
\end{tabular}




\begin{tabular}{|c|c|c|}
\hline Jumalah & $\mathbf{2 0 5 5}$ & $\mathbf{2 5 3 3}$ \\
\hline Rata-Rata & $\mathbf{6 2 , 2 7}$ & $\mathbf{7 6 , 7 6}$ \\
\hline
\end{tabular}

Data peningkatan keterampilan bermain sepakbola siswa dapat dicermati dengan dua tujuan, yaitu: untuk mengetahui peningkatan keterampilan bermain sepakbola secara umum melalui analisis persentase ketuntasan belajar dan untuk mengetahui peningkatan keterampilan bermain sepakbola siswa melalui pendekatan taktis. Analisis tersebut sebagai berikut:

Tabel 2

Prosentase Ketuntasan Belajar Siklus I dan Siklus II

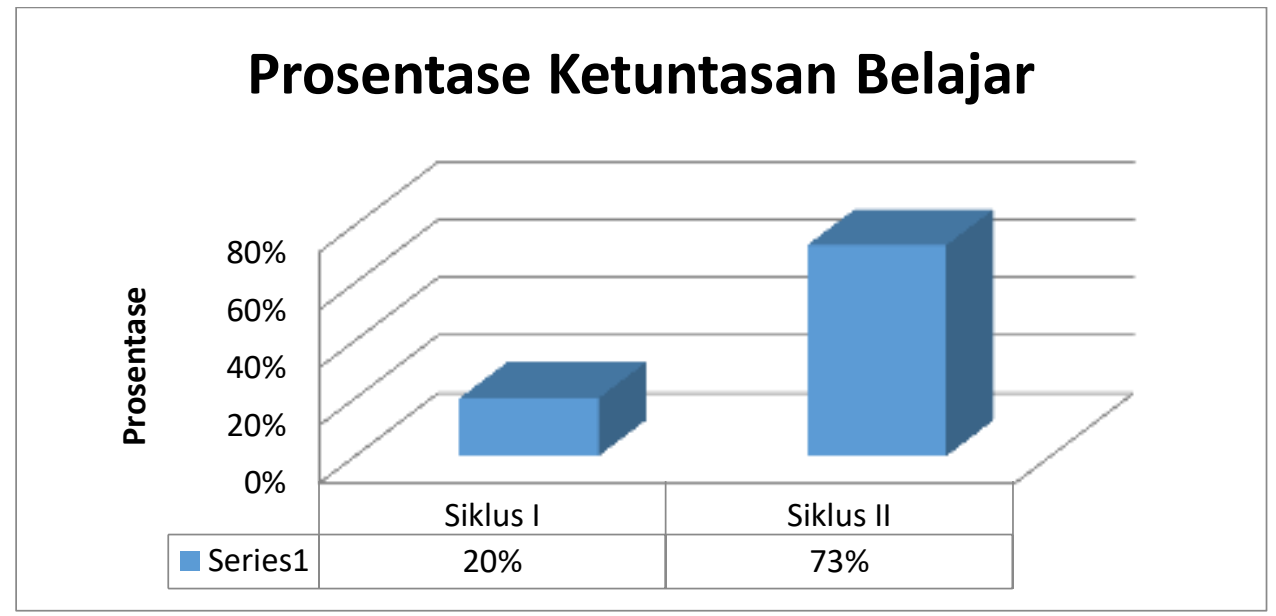

Peningkatan keterampilan bermain sepakbola siswa kelas VIII F di SMP Negri 2 Garawangi secara umum dapat di lihat pada tabel 7 mengenai nilai rata-rata pada setiap siklus yang meningkat. Pada siklus I nilai rata-rata siswa sebesar 62,27 sedangkan untuk siklus II nilai rata-ratanya sebesar 76,76 ini termasuk pada kriteria keberhasilan belajar yang cukup tinggi. Peningkatan keterampilan bermain sepakbola siswa kelas VIII F SMP Negeri 2 Garawangi juga dapat dilihat dari tabel 10 tentang analisis ketuntasan belajar. Berdasarkan tabel tersebut tampak bahwa prosentase ketuntasan belajar pada siklus I ke siklus II mengalami peningkatan yang tinggi yaitu dari $20 \%$ menjadi $73 \%$.

\section{SIMPULAN}

Berdasarkan hasil penelitian tindakan kelas yang telah dilaksanakan melalui beberapa tindakan, dari siklus I dan siklus II serta berdasakan seluruh pembahasan serta analisis yang telah dilakukan, dapat simpulkan bahwa pendekatan taktis sangat tepat untuk meningkatkan keterampilan bermain sepakbola. siswa kelas VIII F SMP Negeri 2 Garawangi. Hal tersebut di tunjukan dari hasil analisis yang didapatkan bahwa nilai rata-rata pada setiap siklus yang meningkat. Pada siklus I nilai rata-rata nilai siswa sebesar 62,27 sedangkan KKM yang 
ditentukan oleh sekolah adalah 73, ini menandakan hasil belajar siswa belum mencapai KKM. Maka dari itu ada tindak lanjut pada siklus II dengan nilai hasil belajar siswa rata-ratanya sebesar 76,76 ini menandakan siswa sudah mencapai KKM sehingga dengan diterapkannya pendekatan taktis dapat meningkatkan keterampilan bermain sepakbola, hal ini di tunjukan bahwa prosentase ketuntasan belajar pada siklus I ke siklus II mengalami peningkatan yang tinggi yaitu dari $20 \%$ menjadi $73 \%$.

\section{DAFTAR PUSTAKA}

Arikunto. (2010). Penelitian Tindakan Kelas. Jakarta: PT Bumi Aksara

Aqib. (2011). Penelitian Tindakan Kelas. Bandung: CV. Yrama Widya Achmad dkk. (2004). Model Pelaksanaan BBE Pendidikan Jasmani Sekolah Menengah Pertama. Jakarta: Depdiknas
Metzler, Michael. W. (2000). Instructional Models For Physical Education. United States of America: A Person Education Company

Subroto. (2001). Pembelajaran Keterampilan dan Konsep Olahraga di Sekolah Dasar. Jakarta: Depdiknas Sucipto. (2000). Sepakbola. Jakarta: Depdiknas

Tarigan. (2001). Pendekatan Keterampilan Taktis dalam Pembelajaran Sepakbola. Jakarta: Depdiknas

Tite, dkk. (2011). Model Pembelajaran Pendidikan Jasmani. Bandung: FPOK UPI Bandung $\backslash$

Sanjaya. (2013). Penelitian Tindakan Kelas. Jakarta: Kencana

Ramadan, G. (2017). Pengaruh Metode Pembelajaran Dan Motivasi Belajar Terhadap Hasil Belajar Passing Sepakbola. JUARA : Jurnal Olahraga, 2(1), 1-10. Retrieved from

http://jurnal.upmk.ac.id/index.php/j uara/article/view/27

Sugiyono. 2012. Metode Penelitian Kuantitatif Kualitatif. Bandung: Alfabet 